\title{
Training Management of Employees in Enterprise Based on Communication and the Psychological Contract
}

\author{
Huangjing \\ University of Jinan \\ Jinan,China \\ e-mail: lcdrose@163.com
}

\begin{abstract}
The staff training can not only promote the occupational skills of the employees, but also satisfy the employees and gains their loyalty, and finally promote the operating performance of the enterprise. The process of staff training can be regarded as a process of building the Psychological Contract between the staff and the enterprise, based on the model of communication and the psychological contract to build the correctional model of the psychological contract with continuous communication. Taking the above as the foundation, the enterprise adopts target strategies in training to improve the quality and results of the staff training.

Keywords-Communication; The Psychological Contract; Staff training;Performance;Encouragement; Training Management
\end{abstract}

\section{INTRODUCTION}

In recent years, the global competitive trend has been speeding up a lot, and as followings, the revolution in enterprises intensifies. Resulting in that the enterprise can not manage and encourage employees by economic contract only, due to the changes of manners and content of work, and more and more enterprises have realized the importance to the psychological contract. The psychological contract is a kind of subjective mentality that agrees things shall be offered and received in the employment respectively to the employers and employees; the core confirmation is the hidden mutual responsibilities of each party [1]. As an invisible bridge, it connects the relationship between the enterprise and its staff, offers an uncountable impact on the human resource management, especially showing its instructive guidance in the filed of staff training.

\section{II .THE FUNCTIONAL ANALYSIS OF THE PSYCHOLOGICAL CONTRACT IN STAFF TRAINING}

There are mainly two impacts on staff training based on the psychological contract: 1) the training based on the psychological contract urges the job performance of the staff. The improvement on the occupational skills can enhance a sense of occupational security, reduces a sense of crises of being eliminated, in favor of one's job skills development, in a higher view, the training is a necessary condition that provides a platform for staff's self realization. Just as the management talent training provided by many organizations, it's a kind of motivator to the staff with potential; 2) the training based on the psychological contract, enhances the sense of identity of employees to the culture and value of the organization. When the employees agree with the value and culture of organization, or rather to say that the individual values coincide with the value of organization, which is suggested as the staff makes self-contribution to the mission of the organization by Andrew Campbell [4]. Dedication is an expression of the coupling of individual values with the value of organization. Therefore, training in enterprise culture and value is a positive factor in impacting the development of the psychological contract.

\section{CONSTRUCTING PSYCHOLOGICAL CONTRACT BASED ON COMMUNICATION}

\section{A Transparency of the psychological contract by continuous communication}

The communicational process model structured by the famous scholar Steven.P.Robinson is the classic representative, which contains the following seven parts: communicating the information sources, coding, information, outlets, decoding, receivers and feedbacks. [5]

In Rousseau's opinion, the psychological contract is mainly structured on the basis of recognizing the operational conditions of organizations and individuals. In this sense, the core of her theoretical model depends on the process of the surroundings and social informational psychology by the individuals. [6]

Communication is the process of constantly coding, decoding and making feedbacks towards the information. From the view of structure model of psychological contact, it can be inferred that the psychological contract is to code and decode towards all the information, and at the same time to take consideration of the process of constant understanding of the business factors. Psychological contract has a characteristic of being subjective and dynamic, whose contents are a sort of subjective sense towards the mutual obligation among the staff and preserve their own experience and ideas. Therefore, it is possible that the staff's psychological expectation may fail to conform to that of the enterprise as well as that of other people's views. Communication and psychological contract have a close relationship by comparing with these two models. Nevertheless, during the process of the birth of the psychological contract or coding and decoding, the agreement of the psychological contract's understanding may be reached by means of interrupting continuous communication.

At the same time, psychological contract owns the features of being dynamic. Basically speaking, normal labor 
agreements are stable, while psychological contract are always in the state of constant changes and modifications. The changes of operational style in business such as the variations of heading, the alterations of ways of communication and the evolutions of the company culture etc. which will surely have an influence on the psychological contract. The longer the staff works in the company, the larger scale the psychological contract will cover and also the easier it can be affected by all sorts of factors. Accordingly, when some factors change in enterprise, the enterprise should make them clearly enough to the staff so that the staffs are able to modify the contents of psychological contract, which all require continuous communication.

\section{$B$ The modification towards the violation of the psychological contract via continuous communication}

There is growing increase in the potential violating the staff's psychological contract as the stiff competition in the inward business and the constantly changeable outer surroundings. Morrison and Robinson who make a summary of the research of this definition about the previous violation towards psychological contract, think that the failure to implement the psychological contract will give rise to some relevant recognition comments and the emotional reactions, between which exists a complicated process of understanding and which emphasize the necessity to distinct the recognition feelings of the failure to implement the promises towards the enterprise from the reactions that are caused by this violation. From the point of them, they hold the opinion that the former means the recognition comments that the staff's replies about the responsibilities for the unfinished psychological contract for enterprise, which is called unimplemented psychological contract; whereas the latter means a kind of emotional experience that bases on the employees failure to implement well psychological contract to the enterprise whose nucleus are agony and disappointment which stems from the staff's ideas of being treated unjustly or the company's not being loyal and responsible, which is named violated psychological contract. [7]

Some other researches that exist currently indicate that unimplemented psychological contract does not necessarily result in negative sides, while violated psychological contract does have bad effects on the attitudes and behaviors of the staff. For example, in a diachronic study, Robinson and Rousseau find that the negative effects from violating psychological contract impair the recognition of the business obligation for the staff. The achievement of the research made by Robinson and her colleagues from the same group of tested employees demonstrates that for the staff, the recognition of the contract violation integrates into some unpleasant behaviors such as an increase in the rate of leaving office, and the degrading of the staff's work accomplishments etc. Hence, there exist some differences between unimplemented psychological contract and that of violation with which exists a bewildered explaining process. [8] The reactions of the staff towards the violation of the contract are for sure disadvantageous in terms of the enterprise. A regulating factor's interference in it may obstruct the transfer from unimplemented psychological contract to violated psychological contract and can even reduce the occurrence of not implementing, which will surely be of paramount importance to the both sides of enterprise and the staff.

\section{IV.STRATEGIES OF TRAINING BUSINESS STAFF TO ESTABLISH PSYCHOLOGICAL CONTRACT BASED ON COMMUNICATION}

The psychological contract based on establishing communicational structures with the staff of enterprises, will pervade into the whole trainings of the company, which will be with the specific purpose of drawing up the training strategies in the process of demand evaluation, the scheme designs, the effect evaluation and the achievement conversion in order to upgrade the training quality and standards of the staff.

\section{A Emphasis of the communication during the training}

The employees in enterprises are all adults who are totally different from those students that are still at school in the process of training study. According to the theory of adult's learning, these staff with real experience of job, just participate in learning with some actual problems, and they are inclined to steer self-instruction, and are also activated or triggered by inward and outward factors to study. Therefore, we must avoid the traditional teaching style---spoon-feeding, and then make the employees take an active part in the training with which lets them join the role reversal and then solidify the training effects. In the process of training, we should emphasize the employees' satisfaction towards the training contents and the training methods by means of making survey questionnaires or making information feedback cards in order to understand the employees' advice and suggestions timely, to know whether those perspectives are suitable or not such as the relations about the training contents and the actual existing problems, the effectiveness of training methods and the difficulties and easiness of the training contents. Understanding all the above information may help to communicate better with training agencies or training teachers. In this way can we remove these phenomena such as employees' complaints about the uselessness of what they have learned, or their failure to put the knowledge that they learnt into practice, so that we can achieve the goal that establishes better psychological contract between enterprises and employees during the training.

\section{B Effect evaluations about training through communication}

It is a significant procedure to evaluate training effects and checking the training results. As long as we lay emphasis on the training's elaborate evaluation, we can improve the training quality and standards step by step. The training effect evaluation not only means that whether training has been done excellently, but also is a process of constant introspecting - which on earth is a more efficient training method, how we can implement the training more 
terrifically. In terms of effect evaluation, we can communicate with the employees via making questionnaires, written tests, role reversals and skill tests and so on and so forth to make our employees take part in the effect evaluations, discern the improvement of the knowledge or skills after they have joined the training as well as their feedbacks towards the training and the suggestions in the future. Evaluating the training effects through the communication with the employees can offer an access to understand the achievement of expectations about training effects, and can also meet the demand of employees' desire of being respected and finally are able to play a part in constructing the psychological contract.

\section{Training transfer on the basis of communication}

Training transfer is the process that the trainees put the knowledge and technologies that they have learned into practice efficiently and constantly. All the employees have the expectation of checking what they have learned in training in the actual working with the purpose of improving their own ability. Consequently, enterprises should create a good working condition for them to utilize the knowledge and skills the moment they just finish the training course. To ensure the training transfer, firstly we ought to offer following service on the basis of the communication with the employees, consulting and solving the problems that the employees have when they work, including offering hotline and the trainers' returning to visit. Furthermore, we make sure of providing enough practices for the employees under the guide of the trainers in order to upgrade the reservation of training contents and the degree of transferring. In addition, communicate with the employees and then ask them to draw up action projects as soon as they finish the training and make it clear that what steps the employees should take to utilize new skills while they get back to their position. Last but not least, be sure to use performance aids to give directions to the employees' actual operations by means of making inspection sheets, decision tables etc.

\section{Linking training with some incentives by utilizing information communication as its tool}

Employees who join the training not only expect to improve their technical competence, but also hope to obtain some relative incentives including material incentives, moral incentives and promotion etc. Accordingly, when the training comes to an end, enterprises had better offer some appropriate awards that they deserved or recognize their outstanding performances for those who have succeeded in utilizing what they have learned during the training into their specific work by means of taking the employees' performances and their application levels in the coming stage into consideration and the enterprises should also meet the demand of the employees' career requirement according to make a general survey of the alteration of their career planning and psychological contract. Thus the employees are able to pick up stronger momentum to continue to join the next stage of the training, which will at last ensure the fulfillment of the sustained and constant development of the training. In consequence, it is indispensable for the enterprises to lay down some relevant policies to inspire a tide of putting what they have learned during the training into actual work. In this way will it be advantageous to achieve the transfers of communicating the employees with the efficient information timely and accurately.

Training the staff is not only a fairly significant way to achieve an increase in human capital, but also is a vital means to upgrade the company's competition. The psychological contract, a tool of retaining the stable relationship, plays a key role in enterprise human resource management and the establishment of the psychological contract must be based on communication. Therefore, in order to realize the goal of enterprise's organization and the objectives of individual and to increase the overall effectiveness of the business activities, it is necessary to build up the psychological contract between the company and the employees on the basis of setting up profound and prevalent communication during the training so that the enterprise is capable of making further progress in improving the quality and the results of the training.

\section{REFERENCES}

[1] Makin, P.J., Cooper, C.L.and Cox, C.J. Organizations and the Psychological Contract: Management of Staff. [M] (England)Wang Xinchao. Translation (2000) Beijing: Peking University Press.22 23

[2] Gary Deshler. The Management of Human Resources [M] (America)Wu Wenfang. Translation (2002) Beijing: China Renmin University Press.231

[3] Edgar, S. Career Anchor: Finding Your Real Value. [M]Beisen Assessing Website Translation (2004) Beijing: China Financial and Economic Press.36

[4] Andrew Campbell. Strategic and Coordination [M] (America)Ren Haitong. Translation (2000) Beijing: Publishing House of Mechanical Industry.227

[5] Stephen. P. Robbins. Organization Behavioristics [M]Sun Jianmin. Translation (1997) Beijing: China Renmin University Press.294 